\title{
The organization activity: a foresight approach of theoretical knowledge evolution in management science
}

\section{A foresight approach in management science}

\author{
Jean-Claude Coulet \\ Centre de Recherche en Psychologie Cognition et Communication, Université Rennes 2 \\ Open lab. Exploration et Innovation, Université d'Auvergne
}

\begin{abstract}
This paper aims to look at the evolution of knowledge in management science, in its dynamic and its relation with the notions of activity and resource, as well as the impact of the general model (input data, processing, output data) used by information processing theories. In this logic, we try to show how the activity approach offers new perspectives, both in terms of the main orientations in resource-based theory ("competence-based management", "knowledge based view", "dynamic capabilities") than on epistemological and foresight plans.
\end{abstract}

\section{Keywords}

Foresight; Theories of activity; Resource-based theory; Competence; Knowledge; Information processing theories

\section{Introduction}

The point of view adopted here has no other ambition than to introduce some elements of reflection about the evolution of the scientific knowledge in management. Therefore, our intention does not constitute, neither a specific and canonical "state of art" in this field, nor an analysis of the different conceptions of the knowledge concept. Much more modestly in this paper, we would try to adopt the point of view of the analysis of activity, in order to describe its contribution to some theories and significant concepts in the management science, when it is used in two directions: on the one hand, as an analyse grid of the more striking evolutions in this scientific field, during the three last decades; on the other hand, as a forecast tool to imagine future evolutions.

For that, initially, we'll describe the main features of analytical framework used, referring to the theories of activity (in particular: Vygotski, 1934/1985; 1934/1997; Vergnaud, 1990; Rabardel, 1995; but also Piaget, 1974a; 1974b; 1975). Then, using this frame of reference, we will focus on the concept of "resource" and the logic of information processing in an attempt to characterize their place in the theoretical developments in management science. This will be made on the basis, voluntary limited, to some epistemological papers, particularly those of Sanchez \& Heene (2010) and Prévot, Brulhart \& Guieu (2010) but also, by using some references to authors which have influenced these evolutions. We will also aim to understand the interest of a few Piagetian concepts to discuss some main conceptions in management science. Finally, with a resolutely foresight point of view, we will seek to consider how these considerations can outline alternative research avenues and may suggest the knowledge management emancipation from the hegemony of information processing theories, where knowledge is conceived like the product of an interpreted information (Pesqueux \& Durance, 2004), that is to say, like a material resource that can be exchanged, stored, transferred... More precisely, it will then be a question of showing that the model (MADDEC) of the competence (Coulet, 2011), presented below, could offer an useful theoretical framework to consider the 
dynamics of the firm as the organization of a specific human activity articulating individual and collective competencies and in which resources are conceived as mere mediating artifacts of the activity.

\section{The analysis of the activity as a reading table}

Traditionally, the theories of the activity are considered as having been introduced by Vygotski (1934/1985; 1934/1997). Thus, the biggest attention is generally given to the concepts of "psychological instruments" (mediation of the activity by the material and symbolic tools, as cultural productions, whose language is the main representative) and of "zone of proximal development" (representing the difference between what the individual can do alone and what it can achieve with the help of others). These concepts have fed many researches, particularly in the field of education and training (e.g. Bruner, 1983; Schneuwly \& Bronckart, 1985; Vergnaud, 1990; Pastré, Mayen, Vergnaud, 2006). They often contributed to emphasize the social dimension of the apprenticeships or the understanding of the individual uses of artefacts (e.g. Rabardel, 1995). However, even though this theoretical approach of the human development (reflecting the triple inspiration of Hegel, Spinoza and Marx) is often opposed (see, for example, De La Ville, 2011) to that of Piaget (characterized by the influence of Kant, Descartes and the evolutionist hypothesis), it must be admitted that the theory of equilibration (Piaget, 1975) represent nonetheless an essential key to describe the characteristics of the human activities organization. The concepts of "scheme" and of "activity regulations" must then be retained as crucial in this theoretical approach, of which it is difficult to say that it is not, too, a theory of activity. Moreover other studies, recently undertaken in this direction, have allowed to specify these contributions. Thus, in his theory of conceptual fields, Vergnaud (1990) provides an analytic definition of Piaget's scheme, considered not only as an organization of the activity for a class of situations, but also as a dynamic whole, constituted by: conceptualizations (operative invariants); adjustments, to incorporate the specific aspects of the situation invested, here and now, (inferences); sequences of actions to produce a effective result (action rules); expectations about these results (anticipations). For its part, Rabardel (1995) articulates directly the concepts of scheme and of psychological instrument by providing a model of instrumental genesis where are highlighted the concepts of "instrumentalisation" and "instrumentation". Respectively, these concepts correspond to the selection (or transformation) of the properties of the artefact, according to the characteristics of the scheme that is used, and on the other hand, changes of the scheme depending on the properties of the artefact. This author also highlights the dual function of the activity (Samurçay \& Rabardel, 2004): directed towards the production of a result (productive activity) and the capitalization of experience (constructive activity). For its part, Coulet (2011), in the perspective of these works, proposes a model of competence, characterizing the organization of these two functions of the activity (cf. figure 1): mobilization of a scheme (with its components such as described Vergnaud, 1990), mediated by artefacts (Rabardel 1995) and reorganized (Pastre, 1997; Leplat, 2006) with three regulation loops: a short loop of regulation on rules of action, a long loop of regulation on conceptualizations (operative invariants), a regulation type "change of scheme" concerning the reorganization of the system of activity in which is included the mobilized activity.

Moreover, the author considers that this model is also relevant in order to describe the collective competences (see, in particular, Coulet, 2013a; Coulet, 2013b; Coulet, 2014). Therefore, it is possible to use it as a reading grid of the activities' organization of a community such as, for example, a group of scientists, in a given subject area. It is this analytical framework that we propose to use to try to identify some characteristics of the collective activity that led to make the concept of resource one of the most important in management science (Prévot, Brulhart \& Guieu, 2010) and, also, to develop models 
responding implicitly to the logic of information processing. Of course, as already pointed out, our objective is not here to draw up a rigorous and detailed genealogy of all the researches concerned, but rather to put forward a very macroscopic approach of their general evolution, in an essentially exploratory purpose, aiming to feed the investigation of future potential evolutions (see $\S 6$.).

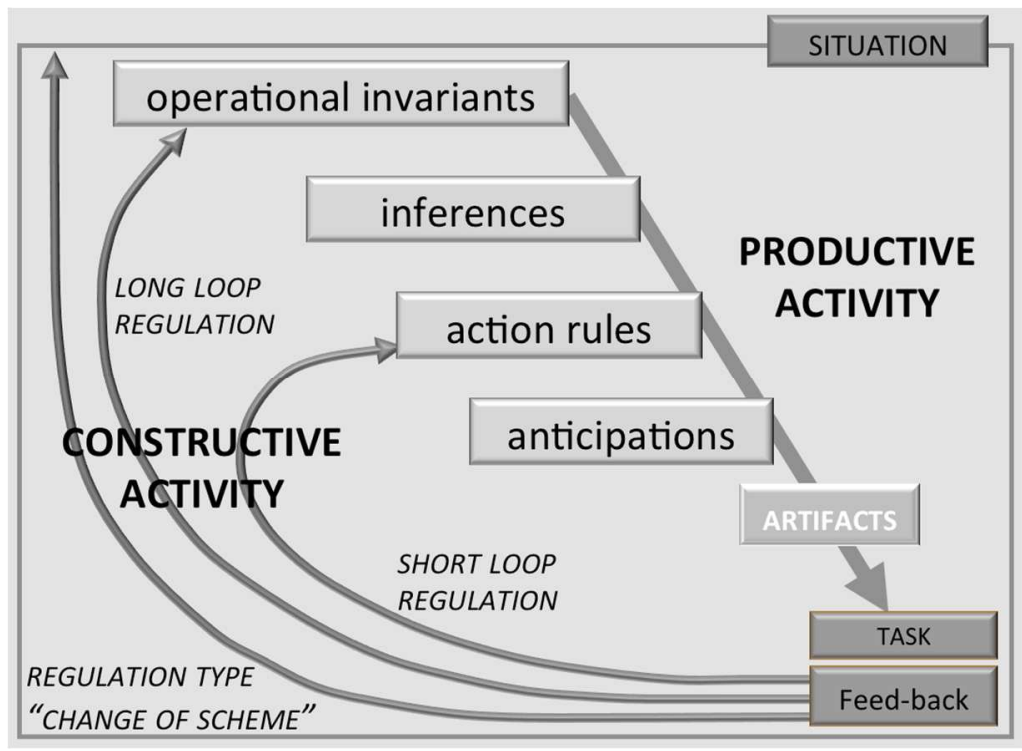

Fig. 1 - MADDEC ${ }^{1}$ (Coulet, 2011)

\section{The concept of resource}

\subsection{The context of its emergence}

With preoccupations mainly oriented on the performance of the firm, the concept of resource has been promoted in break with the approach based on the structure of the industry highlighted by Porter: "Industry structure has a strong influence in determining the competitive rules of the game as well as the strategies potentially available to the firm" (Porter, 1980, p. 3). Indeed, if we follow the analyses of Sanchez \& Heene (2010, p. 113114), we can oppose: "the end of the seventy years and the eighty, during which the dominant theory in researches on strategy was the paradigm based on industry structure, borrowed from the industrial economy and mainly put forward by Porter (1980, 1985)" to the "years ninety and the following ones, during which the theories on strategy has been mainly influenced by the paradigm based on resources, result of Penrose's work (1959) and Wernerfelt (1984) and highlighted by Barney (1986, 1991)",2.

\subsection{The use of the analysis grid}

By adopting the analysis grid presented above, we can make the assumption that the organization of the research activity, in this area, is describable in terms of collective scheme, mobilized by the scientific community here concerned. Indeed, it is possible to consider that this activity is a collective one, functionally organized by this community, whose goal is quite clearly recognized by all its members, which ensure its implementation, with:

- consensual expectations concerning the results (anticipations);

- achieving scientific productions, by individual researchers and research teams, to generate the desired results (action rules);

\footnotetext{
${ }^{1}$ MADDEC: Modèle d'Analyse Dynamique pour Décrire et Evaluer les Compétences (Dynamic Analysis Model to Describe and Assess Competences).

${ }^{2}$ Our translation.
} 
- adjustments of the rules of action, depending on the circumstances in which the research is conducted (inferences);

- conceptualizations, recognized by all researchers and usually formalized in the publications of the scientific community (operational invariants) including:

- elements considered as true (theorems-in-action), particularly, all knowledge formalized in reference literature as theories and research results, shared values regarding to, for example, the ethic, the standards, the beliefs, etc.;

- elements considered as relevant (concepts-in-action), particularly those that affect the success of a research activity: the nature of the data to be collected, the population concerned by this collecting, the nature of the data processing used, the quality of the publication support, etc. ;

- material tools (computers, data processing, publishing media, etc.) and symbolic (language, jargon, diagrams, etc.), which mediate this research activity (artefacts).

In other words, this collective research activity presents effectively all the characteristics of a scheme (such as it is described by Vergnaud, 1990), instrumented (Rabardel, 1995) and of a very general type, expressible as: "description and explanation (or prediction) of the differential performance of organizations".

\subsection{Researches based on the structure of the industry}

Furthermore and even more specifically, this scheme could be characterized (in the period situated by Sanchez \& Heene in the late of seventies and during the eighties, dominated by the reference to the structure of the industry), by :

- as highlighted by these authors, a clear objective (anticipation) that aim to have a "theory to explain the outcomes of competitive interactions among firms in all

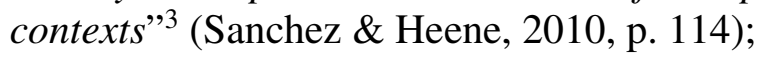

- the researches production (action rules), that could contribute to the achievement of this result by showing that "success in competitive interactions" is congruent with "the occupied position by the firm in the structure of its industry" (ibid.);

- adjustments (inferences) of research work implementation modalities, depending on the context in which they are deployed, especially in light of already established results;

- mobilization of conceptualizations (operative invariants) associated with the research activity undertaken and marked by:

- elements considered as true (theorems-in-action), such as: "structural analysis shows how a firm's existing strategic position coupled with existing industry structure translates into performance in the marketplace » (Porter, 1980, pp. 151-152), "an industry structure is mainly defined by the concentration of market share among competitors in an industry", "the position of a firm in the structure of an industry is defined by its relative market share compared with other actors" (Sanchez \& Heene, 2010, p. 114), "if a company has greater market share than its competitors then it will have a market power and lower costs", etc. ;

- elements considered as relevant (concepts-in-action), in research processes, such as, for example: "market share", "costs", "prices", "advantage" (as variables taken into account); the "state of the art", "ethics", "feasibility" (as important elements in the research process), etc. ;

\footnotetext{
${ }^{3}$ Our translation.

4 Our translation.
} 
- the use of research tools (artefacts) conventional (or more original): from the data collection techniques, to the formulation of research reports in compliance with publication standards, etc.

As for the regulations of this collective scheme, the "long period of theoretical success" [...] "in terms of prediction of the relative profitability of firms" Sanchez \& Heene (2010, p. 114), can be read as a contribution to the development of short loops of regulation, with the main aim to ensure "the creation of a continuous process of theoretical development which studies different strategies to improve and use the position of a firm in the industry (expansion of capacity for preventive purposes, construction of barriers to entry so as to prevent new entrants to change the current structure of the industry, control of newcomers that threaten

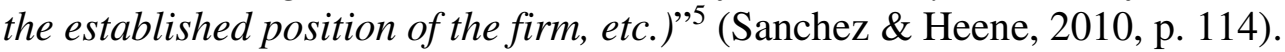

\subsection{A conceptualization change}

Nevertheless, such short loops of regulation find their limits especially when, according to Sanchez \& Heene (2010, p. 115): "industries have undergone significant technological changes that led to the emergence of new concepts of products and even, new industries, new variables concerning the firm such as the speed of products development and the capacity to create synergies in the use technologies between different product lines, have become important determinants of profitability". Thus, "at the end of the years eighty, largely in response to the failure of the theory of the structure of the industry to recognize and take into account the sources of heterogeneity potentially important firms (beyond their current positions in the industry), the theorists in strategy began to consider the distinctive resources and capabilities of firms as new basis for predicting success and competitiveness and so, to develop a theory about strategy" 6 Sanchez \& Heene (2010, p. 115). From this perspective, the Wernerfelt's article (1984) has clearly played a decisive role, in this evolution of the collective research activity and in promoting the notion of resource as a major source of the firm's profitability: "It is possible to identify classes of resources for which resource position barriers can be built up. By their nature, these barriers are often self-reproducing; that is a firm which at a given time, finds itself in some sense ahead of others may use these barriers to cement that lead. It is the properties of the resources and their mode of acquisition which allow this to be done » (Wernerfelt, 1984, p. 173). In reference to our analysis grid, we can then interpret this development as a long loop of regulation of the above-described scheme. Indeed, it is possible to postulate that among the operative invariants previously mobilized by this scheme, (relevant in a relatively stable environment) a theorem-in-action such as: "If a company has a larger market shares than of its competitors, then it will have market power and lower costs"7 has lost its value, in a context of rapid environment changes, for the benefit of another, such as: "the nature of distinctive resources of firms and those they are able to acquire exclusively, explain their profitability". Furthermore, the concepts-in-action related to "resources of the firm" take then an important place to the detriment of those previously linked to "position of the firm". Of course, as we shall see, such a conceptualizations change, associated with the research scheme, is not without consequences on the ways to mobilize it (action rules). Nevertheless, we must admit that it basically remains the same because the

\footnotetext{
5 Our translation.

${ }^{6}$ Our translation.

${ }^{7}$ In this regard, Depeyre (2005) analyses the position of Wernerfelt (1984) in this way: "Every company strives to create and to develop resources that ensure its persistent advantage over its competitors. This advantage is depending either of the properties of the resource itself or of the ability of the firm to acquire these resources by making difficult this acquisition by the competitors (Wernerfelt advance the concept of resource position barrier that he brings closer and distinguishes, at the same time, of traditional barriers to entry)" (our translation).
} 
research community works focus still on the "description and explanation (or prediction) of the differential performance of the firms".

\subsection{Changes in the practices}

\subsubsection{DEVELOPMENT OF RESOURCES TAXONOMIES}

Unquestionably, a theorem-in-action such as: "the differential performances of the firms are explained by the nature of their distinctive resources and those they are able to acquire exclusively" is a pretty strong incentive to a research work (action rules) oriented on resources taxonomies and this, especially as the examples given by Wernerfelt give way to many possibilities: "By a resource is meant anything which could be thought of as a strength or weakness of a given firm. More formally, a firm's resources at a given time could be defined as those (tangible and intangible) assets which are tied semipermanently to the firm (see Caves, 1980). Examples of resources are: brand names, in-house knowledge of technology, employment of skilled personnel, trade contacts, machinery, efficient procedures, capital, etc. » (Wernerfelt, 1984, p. 172). It is therefore not very surprising to note then that Barney (1991) proposes to characterize, among all the resources that condition the profitability, those seem to be the most crucial; that is why he moves forward the VRIO frame (The resource must be creative of value $(\mathrm{V})$, rare $(\mathrm{R})$, inimitable (I) and integrated in the organization $(\mathrm{O})$ ). It is not surprising to see also formulated criticisms concerning researches that have followed the Wernerfelt's and Barney's proposals. Regarding these works, Sanchez \& Heene (2010, p 117) point out: "The epistemological consequence of accumulation of empirical findings under the banner of the resource-based theory has been a cacophony of discoveries that have no coherent conceptual base to allow for future developments and

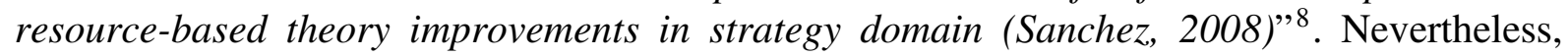
these authors continue to advocate for the development and clarification of the concept of resource in order to creating taxonomies: "On this basis, we conclude that the concept of resource must be considerably clarified and developed beyond the Barney's conceptualization, essentially by creating taxonomies and / or typologies identifying the kinds of resources that will have different abilities to contribute the success of the firm in a variety of competitive contexts"9 (Sanchez \& Heene, 2010, p. 118).

\subsubsection{THE IDENTIFICATION OF KEY FACTORS OF THE RESOURCES USE}

However, they point out, following (Sanchez \& Heene, 2010, p. 118), the need to consider also: "the fundamental factors affecting the use of resources by the firm: capacities that the firm can mobilize to support use of resources, the processes that a company uses to coordinate its resources and capacities in value creation, the management processes that a company uses to attract, retain, maintain and boost its resources, and the strategies that a firm adopts to position and deploy its resources and capacities in its markets" ${ }^{10}$. Are thus emphasized the key elements that will be retained by other categories of works whose originality will essentially be to organize what can be interpreted as another rule of action complementary to that consisting to identify categories resources with a greater or lesser influence on the performance of the firm.

\subsubsection{THE ORGANIZATION OF THREE RESEARCH CURRENTS}

\footnotetext{
${ }^{8}$ Our translation.

${ }^{9}$ Our translation.

${ }^{10}$ Our translation.
} 
The first of these research currents, has been developed under the appellation "competencebased management" (Prahalad \& Hamel, 1990), focusing on (Sanchez \& Heene, 2010, p. 119): the firms capabilities ("reproducible action modes in the use of resources"), the management process ("to attract, develop, stimulate, coordinate, and deploy resources and capacity"), the strategic logic ("to keep the creation and distribution of value through the deployment of its resources and capacities in its markets") and competences ("ability of the organization to support the coordinated deployment of its resources and capabilities to enable the achievement of its objectives"). Moreover, contrary to the approach based on the structure of the industry, the environment is here considered as unstable, leading some authors (Sanchez, 1996) to distinguish types of markets (e.g. "stable, changing, dynamic") and to identify a typology of actions (a priori favourable to the performance of the firm) by crossing the four factors identified by the "competence-based management" with the three types of environments (see Sanchez \& Heene, 2010, table 1, p. 121). As for the definitions of the competence, Prévot, Brulhart \& Guieu (2010, p. 92) ${ }^{11}$ make a critical analysis highlighting three levels of definitions in the "competence-based management" approach:

- firstly, competence is seen as "a complex organizational 'alchemy' that comes from interactions between knowledge (personal or present at the organizational level as a whole), practices and attitudes (Durand, 2000)";

- secondly, it is put forward " a connection between the competence and the results of its implementation. The competence only makes sense if it allows to activities a greater competitiveness, that is to say in order to bring to the products a superior functionality for customers compared to the competing products (Prahalad and Hamel, 1990; Doz, 1994)";

- thirdly, the "distinction between the competence and the resources" is highlighted and the competence is seen as "the way of coordinating resources allowing to accumulate and develop resources and create new ones (Arrègle, 1995)".

The second category of researches (initiated by the contributions of Kogut \& Zander, 1992; Conner \& Prahalad, 1996; Spender \& Grant, 1996, cited by Provost \& al., 2010) and typically identified as "knowledge based view", sees the knowledge as a privileged element in the explanation of the organization of the productive tasks and some authors as Nonaka \& Takeuchi (1995), emphasize the dynamics of knowledge within the firm and point out the need to take into account the relationship between the individual and collective dimensions. Four phases are then developed by the authors to explain this constructive dynamics: a phase of "socialization", allowing interpersonal exchange of tacit knowledge, a phase of "externalization", in which some are clarified to become explicit knowledge, a phase of "combination" characterizing their passage from individual to collective level in creation of new explicit knowledge, and finally an "internalization" phase, characterized as an appropriation, at the individual level, of collectively created explicit knowledge. Thus, searchers have been encouraged to explore two important dimensions of the firm, in connection with its idiosyncratic aspects that give it a competitive advantage: the articulation between tacit and explicit knowledge on the one hand, the relationship between individual and collective levels, on the other.

The third category of research concerns the approach based on "dynamic capabilities", introduced by Teece, Pisano \& Shuen (1997). This approach emphasizes the fact that the evolution of the firm is strongly conditioned by the resources it has accumulated in its history ("path dependency") and, furthermore, on the dynamics of experiential learning which leads it to develop new skills, generating innovation. It is then emphasized, through the concept of "competitive flexibility" (Teece et al., p. 513), the importance, for the firm, of a "dynamic"

\footnotetext{
${ }^{11}$ Our translation.
} 
adaptation, required to face variations of its environment and this position is referred to different types of works: "Elements of the approach can be found in Schumpeter (1942), Penrose (1959), Nelson and Winter (1982), Prahalad and Hamel (1990), Teece (1976, 1986a, 1986b, 1988) and in Hayes, Wheelwright, and Clark (1988)" (Teece \& al., p. 510). As for the available levers to manage dynamic capabilities, they are of three types (Teece, 2007: 1319): "For analytical purposes, dynamic capabilities can be disaggregated into the capacity (1) to sense and shape opportunities and threats, (2) to seize opportunities, and (3) to maintain competitiveness through enhancing, combining, protecting, and, when necessary, reconfiguring the business enterprise's intangible and tangible assets".

\section{The reference to information processing theories}

The very fast and very schematic overview of the works presented above provides a glimpse of the great conceptual richness of the literature on what, according to our analysis grid, we propose to consider such as the implementation (action rules) of the general research scheme "description and explanation (or prediction) of the differential performance of organizations". As we have seen, the concept of resource (as operative invariant) is clearly at the heart of all these works. Beyond this, we have yet to see what is their general conception of the underlying process describing the links between the characteristics of the environment and the firm to explain its performance in terms of competitive advantage.

\subsection{A common underlying conception}

From this point of view, despite the distance they put with the works considering the firm as an "information processor" (Cohendet \& Llerena, 1999), it seems pretty clear that the reference to the mechanistic diagram (input data - processing - output data), widely used by the information processing theories, is still very present in the various currents coming from the resource-based theory. Indeed, this one considers mainly that it is the external and internal resources, "exploited" and "explored" (cf. March, 1991), that allow the performance of the firm, that is different from other firms both, by the nature of the resources exploited and explored and by the means used to do so. This may be schematized as follows (fig. 2).

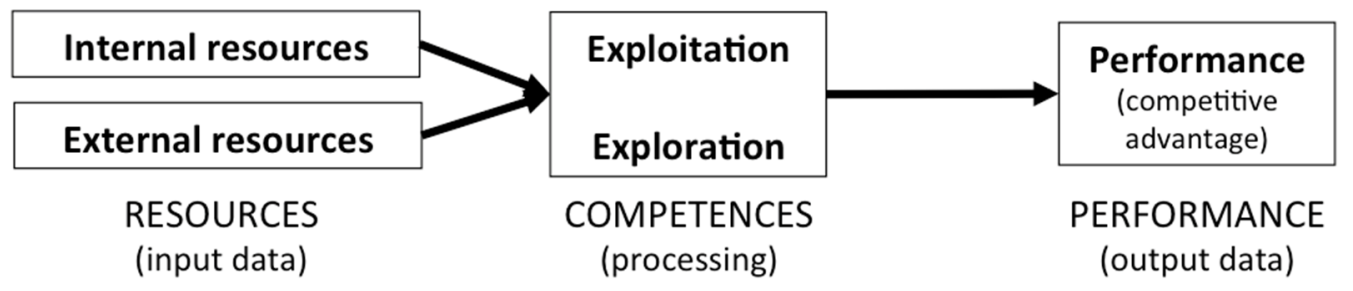

Fig. 2 - Schematic representation of the resource-based theory

Obviously, such a schema is entirely consistent with the basic model used by the information processing theories: input data are transformed by one (or more) module (s) to produce output data. Of course, this basic schema can become more complex if it is included in a set of modules operating in the same way or if we try to explain identically, for a given module, its internal functioning.

\subsection{Specificities}

For example, can we consider that the "competence-based management" is expressed quite easily by the schema in figure 3 (below), provided that each of the actions mentioned in the central box is expressible by a schema of the type shown in figure 2 . 


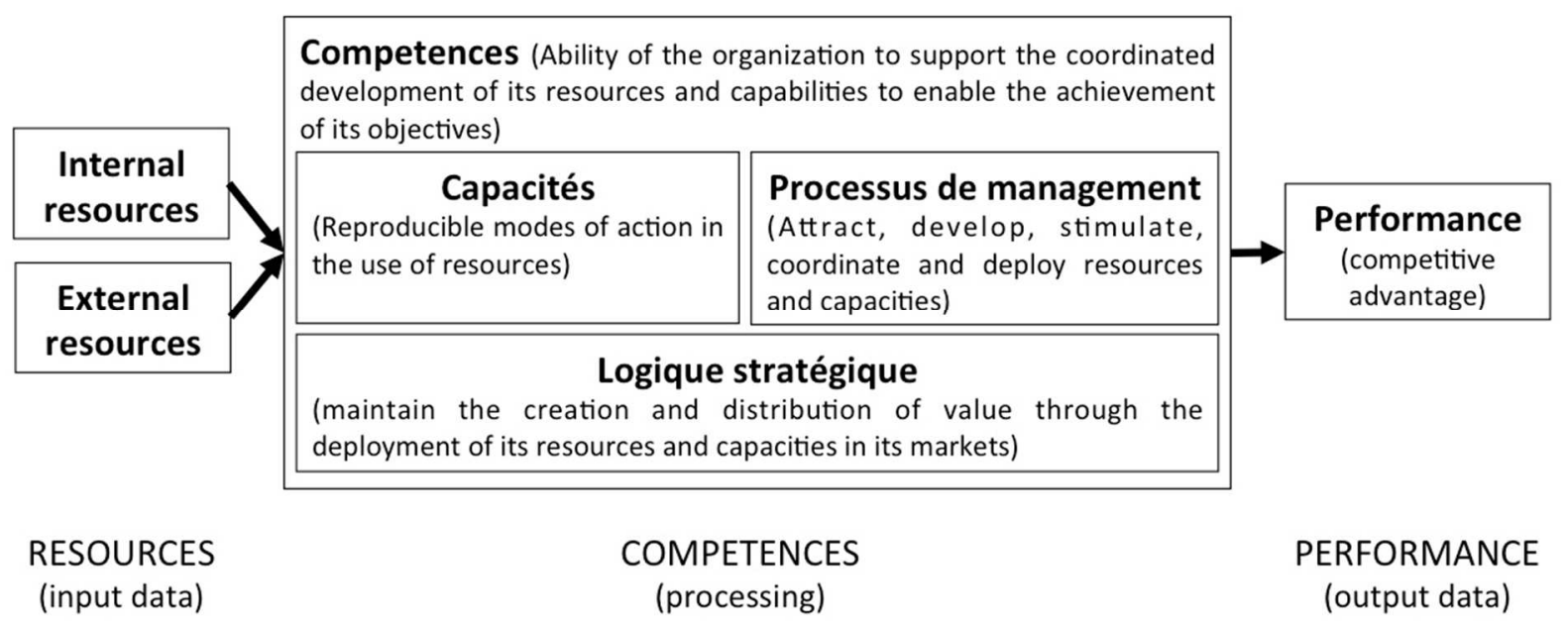

Fig. 3 - Schema of the "competence-based management"

In this light, the "competences" module integrates three sub-modules ("capacities", "management" and "strategic logic"), each of them implementing a number of actions that could describe the input and output data; their combination, by the "competences" module, producing the overall performance. On its side, the proposal by Sanchez \& Heene (2010, p. 124) to develop empirical researches, that would validate their theoretical conception, reveals also a vision rather mechanistic: "The launch and development of a structured research process would require a core group of researchers, trying to clarify the concepts together, in order to develop taxonomies and typologies of competitive environments and to represent the sources of heterogeneity of firms that are significant in a perspective strategic" 12 . In other words, this search for performance optimization from a characterization of the environment, on the one hand and competences of the firm, on the other hand, in terms of taxonomies that must be linked (see Sanchez \& Heene, 2010, fig. 6, p. 122), appears as a strategy that could be ideally automated in a type of program: "if environment 1, then action 1"; "if environment 2, then action 2", etc., drawn from the purest mechanistic tradition of information processing. Quite similarly, the other two research currents described previously ("knowledge based view" and "dynamic capabilities"), could be schematized in the same way, insofar as either one assume also exploitation and exploration (the central box, which only the content would be somewhat different) and external and internal resources to produce a performance expressed by a competitive advantage. Indeed, the "knowledge based view" considers knowledge as resources, both internal and external (input data), whose the exploitation / exploration (e.g. via the four phases of conversion of tacit knowledge into explicit knowledge described by Nonaka \& Takeuchi, 1995) make possible to create new ones which help to develop idiosyncratic aspects of the functioning of the firm (treatment), providing a competitive advantage (output data). For its part, the approach based on dynamic capabilities, identifies relevant resources ("sensing") present in its environment (input data), adjusts them to the characteristics of its current functioning to remain competitive ("seizing") and, if necessary, operates reconfigurations ("transforming") of its tangible and intangible assets (processing) to increase its performance (output data).

\subsection{Important consequences}

Although the previously mentioned works do not fall, on the contrary, within the information processing theories (considering the emphasis respectively placed on competences, knowledge, dynamic capabilities, not on information), the pervasiveness of the generic model

\footnotetext{
${ }^{12}$ Our translation.
} 
(input data - processing - output data) is not without consequences on the theoretical frameworks used.

\subsubsection{A LINEAR CAUSAL LOGIC}

First, it must be noted that the generic schema (input data - processing - output data) implies an attention paid to each of these three elements, while making them dependent on each other in a linear causal structure. Thereby, when it guides researches in management science, it imposes this logic into elaborate theories. Thus, in the conventional modelling of the firm interaction with its environment, the resources are considered as an obvious starting point (and therefore not questioned as such) of the performance of the production process. Similarly, the latter is not particularly discussed by the different currents derived from the resource-based theory, so much the approach based on the structuring of the industry seems to have definitively promoted the competitive advantage and the profitability as the preferred dependent variables. As for the process establishing the causal link between resources and competitive advantage and / or profitability, as we have already shown, they appear largely reduced to the actions taxonomies supposed to ensure more or less judicious combinations of these resources to deliver the performance of the firm.

\subsubsection{MECHANIST EXPLANATIONS}

Moreover, in this approach, the input data (here the resources) are envisaged in an absolute way: they exist on their own basis and appear as placed on shelves (possibly into categories logically elaborated) where it seems easy to tap into, without much constraint (other than the acquisition cost) to power the production processes of output data. In doing so, the relationships they have with the processes are understood as those that can have two pieces of a clockwork in their purely mechanical ratios. Thus, it is not unusual (and even very common) to see knowledge considered in the chain schematized in figure 4, illustrating a process of genesis, very representative of the impact of information processing theories. It is then explained that after their passage through a module "insertion in a context", data (input data) become information (output data), that a new module "interpretation" integrates as input data and transforms into knowledge (output data) and that their integration (input data) and transformation, this time performed by an "application" module, mutates into competences (output data).

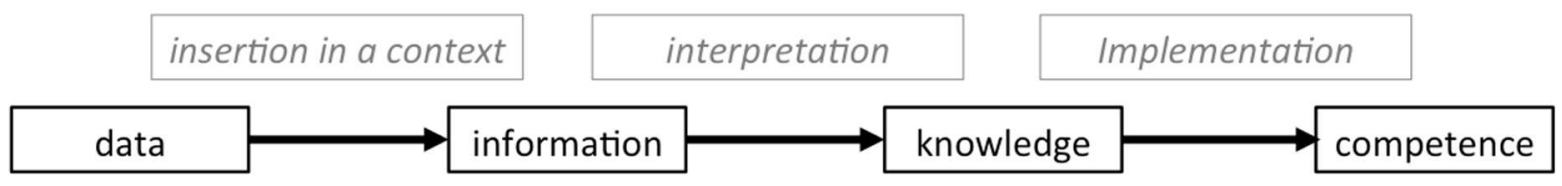

Fig. 4 - From data to competence

\subsubsection{DESEMBODIED RESOURCES}

Moreover, in this type of theoretical framework, resources (as an input data) have no reason to be considered very differently, depending on whether they are material resources or "human resources". In both cases, their primary function is to provide data to a process that does not have to adapt its functioning depending on whether these resources are material or human ones. In other words, the risk is great to see these information processing models overshadow large sectors of knowledge concerning the interactions between individual and collective competences and the artefacts they use in the activities they organize. This can also result in ignoring if these competences depend on resources of the firm or processes that use them. In this regard, the contributions of the theories of the activity (including works initiated by Piaget) seem major both for understanding these interactional mechanisms than for discuss 
the status, in the resource-based theory, of concepts of competence, knowledge, and dynamic capabilities, respectively highlighted by the "competence-based management", the "knowledge based view" and the "dynamic capabilities".

\section{Conceptual analogies to be highlighted}

Through the theory of equilibration, Piaget (1975) provides in fact some major conceptual benchmarks we recall here very briefly.

\subsection{An adaptive interaction}

There are first, the two processes (assimilation and accommodation) that Piaget poses as those that ensure the adaptation of living organisms to their environment, considering that it is the activity that carries this adaptation. By analogy, and without forcing the line, we see that it is possible to consider the firm, otherwise as a living in the strict sense but, at least, as an entity that has an active interaction with its environment. As such, as illustrated by the development of management science research mentioned above, the firm must adapt itself to an environment that often progresses rapidly (see for example, the concept of "competitive flexibility", Teece et al., p. 513). In other words, the competence of the firm is to be regarded primarily as adaptive organization of its activity.

\subsection{The importance of the history}

However, this competence assumes that elements of the environment (and in particular changes) are perceived and integrated by the firm (assimilation) in order to adapt its activity to these and / or their variations (accommodation). Yet, what Piaget shows very well is that this comparison is not done by simple contact. Rather, he insists on the fact that any assimilation depends on assimilative structures already built. In other words, (to go back on an image already used) to draw on a shelf (even well-organized), depends primarily on the level of acquired competence to do it, that is to say, of the history of the activity. Again, one can recognize the presence of similar concepts in management science, especially inspired by the evolutionary approach, through, for example, the concept of "path dependence" (Nelson and Winter, 1982).

\subsection{The status given to the knowledge}

Moreover, for Piaget, it is clear that if the knowledge plays an important role in the assimilation activity, this one is far from to be exclusive, contrary to what might be suggested by the knowledge-based approaches from the resource-based theory. Piaget is also breaking with the conception of "knowledge as an object" (such as it appears in figure 4) and emphasizes, on the contrary, the very close relationship existing between knowledge and activity: "Knowing does not lie in copying reality but in acting on it and in changing it" 13 (Piaget, 1967, p. 23).

\subsection{The process of change}

As for accommodation, Piaget shows that it corresponds to a reorganization of the assimilative structure, including significantly, when, for example, a scheme (assimilative structure) is differentiated into several subordinate schemes (differentiation) or when it is integrated into a higher-level scheme (integration). Here again, the approach based on dynamic capabilities, distinguishing "Weak ordinary capabilities", "Strong ordinary capabilities" and "Strong dynamic capabilities" Teece (2014, p. 21, Table 2) mark, in some way, a hierarchical conception of the organization (here, of capacities, understood as structures of the activity of the firm). However, in this theoretical framework, we do not find

\footnotetext{
${ }^{13}$ Our translation.
} 
a single element aiming to explain these hierarchical relations through processes such as those proposed by Piaget in terms of differentiation / integration. Furthermore, these three types of abilities appear much more juxtaposed than truly integrated in a unique framework reflecting both, their functional relationships and their processes of mobilization and of construction: the three essential elements ("sensing", "seizing" and "transforming") are here considered as common information processing modules, functioning in the logic of those that have been presented above (see fig. 2 and 3).

\subsection{The concept of scheme}

In Piaget's approach and in works which come therefrom (in particular these of Vergnaud, 1990), the central concept of scheme refer to any other logic: it is, above all, an organization of the activity for a class of situations and integrated into a scheme system that operates by differentiation and integration. Moreover, it can be analytically described (Vergnaud, 1990) as the implementation of a productive activity (Samurçay \& Rabadel, 2004) to perform a task, which involves its reorganization by regulations (Piaget, 1975) of various forms (Coulet, 2011) characteristic of its constructive activity (Samurçay \& Rabadel, 2004). The scheme also involves processes that manage mediations of the activity by artefacts (see the concept of psychological instrument in Vygotsky, 1934/1997 and processes of instrumentalisation and instrumentation in Rabardel, 1995). In other words, the scheme refers both to a structure and to a situated activity. We can on this, once again, notice that some concepts, commonly used in management science, attest to the interest of the approach to the organization of the activity, beyond broad denominations (competences, knowledge, dynamic capabilities, routines, etc.). For example, the concept of "organizational routine", which is addressed in the conventional sense as: "a repetitive, recognizable pattern of interdependent actions involving multiple actors" (Feldman \& Pentland, 2003, p. 96) has been the subject of a more detailed analysis from Feldman \& Pentland (2003), proposing to distinguish the "ostensive" aspects (related to its structure) and the "performative" aspects, expressed by "the specific action taken by specific people at specific times when they are engaged in an organizational routine" (Feldman \& Pentland, 2003, p. 101-102). In doing so, we can only notice a strong analogy with the properties of the scheme, mentioned above, even though these authors make no mention of this concept.

\subsection{A general observation}

These brief comments ${ }^{14}$, around analogies that can be established between an approach anchored in developmental psychology and theoretical frameworks that characterize the management science, express a fact that can be summarized as follows:

- although the analysis of the activity is not considered as such in the various versions of the resource-based theory, it turns out that there are a set of concepts and considerations that seem implicitly consistent with it ;

- however, the status given to the notion of resource and the impact of information processing theories appear as two strong resistance points, in management science, in order to give to the theory of activity a role which is not limited to a few initiatives (see for example, in France, the number 2, 42, of the Management \& Avenir magazine devoted to Vygotski; Gilbert, Raulet-Croset, Mourey \& Triumph, 2011; Lorino, 2009; Lorino, 2013).

\section{A foresight approach of the evolution of theoretical knowledge in management science}

\footnotetext{
${ }^{14}$ A systematic work in this respect would deserve to be led in order to go much further.
} 
We now propose to take back our reading grid of the evolution in the collective research activity, in management science, in order to try to see what we can deduce from analyzes presented above, by adopting a foresight perspective.

\subsection{Recall of the analysis of past evolutions}

Having shown that the activity of management science research can be read as the mobilization of a collective scheme, we have successively advanced, in the point 3 , what is following.

First, we considered that it could be globally identified as: "description and explanation (or prediction) of the differential performance of organizations". We then showed that such a denomination is relevant as well to characterize researches of the period dominated by the industry structure, than to describe these that have followed around the resource-based theory. More specifically it was shown how, in the first period, short loops of regulation (amendment of rules of action) are sufficient to provide descriptions, explanations and even generally satisfactory predictions. We have also highlighted that the advent of the resource-based theory, in the researches that followed, can be read as a long loop of regulation (changing a key concept): the concept of resource takes then precedence over the of industry structure but the overall scheme remains the same and only, its action rules are adapted to the new conceptualization. These action rule changes have then adopted three different ways to treat the use ("exploitation"), the research and creation of new resources ("exploration") and preferring to do that, using respectively: the "competences-based management"; the "knowledge-based theory" and the "theory based on dynamic capabilities". However the notion of resource remains the central pillar of these conceptualizations that stay tied to a research implementation always oriented by the "description and explanation (or prediction) of the differential performance of organizations".

\subsection{A reading of a possible future evolution}

The entry through activity analysis, that we have chosen, as reading grid of the knowledge evolutions that impact the research activity in management science, leads us to consider a new foresight approach of these evolutions. This one consists in successively and systematically explore each of the three loops of regulation available for the scheme "description and explanation (or prediction) of the differential performance of organizations". Obviously, our perspective, on the management science from developmental psychology, is very limited and what follows aims only to formulate some considerations based more on overall impressions than on a thorough knowledge of this domain. Indeed, while the retrospective analysis presented above, is justified by expert viewpoints of the domain, a foresight analysis is much more difficult to drive for a non-specialist. Nevertheless, this exercise merits certainly to be tempted, even if it may be only useful in establishing a constructive debate.

\subsubsection{SHORT LOOPS OF REGULATION}

Today, resource-based theory seems to benefit from a consensus still very important, giving it a status of "normal science" (as defined in Khun, 1983), even if we can see an emergence of viewpoints likely to raise crucial issues. So it has, probably, a significant future, marked by numerous short loops of regulation of the research activity in order to refine the different variables, data and concepts that characterize it. A detailed analysis of these different elements in researches recently published would allow, undoubtedly, the identification of some relatively original directions to do that with variable degrees of success to produce an impact on the implementation modalities of the scheme that we have characterized. In light of our analysis, we can thus assume that, for example, a different definition of competences or knowledge could be the source of relatively original empirical researches in the "normal 
science". The same could be said about an increased focalization on the processes involved in the link between dynamic capabilities and routines.

\subsubsection{LONG LOOPS OF REGULATION}

Concerning the long loops of regulation, one might think that a change, as important as that which marked the transition from the prominence of the industry structure to that of resources, could occur if the concept of activity become sufficiently consensual among researchers, so that it could break up the supremacy of that of resources. Indeed an emphasis put on the activity could appeal in knowledge constituted by the theories of the activity. From this point of view, the elements provided above allow to understand easily the changes thus generated. For example, it is possible to think that, in this case, the conception of the relationships between resources, competences and performance would be fundamentally upset. Indeed, it is quite easy to imagine that a model as MADDEC (Coulet, 2011) could allow to see competences as an organization of individual and collective activities describable, for example, as a system of schemes which the characteristics could be analysed through reference tables of competences theoretically based. We could then, on this basis, foster the emergence of some individual and collective competences, hitherto remained in the implicit, in order to promote changes in organizational routines. This could be carried out, in particular, through working on the deviations existing between prescribed work and real work (cf. Coulet, 2014). More generally, the spiral-model of strategic management, proposed by this author, could allow to test many other assumptions that have, probably, never been formulated so far, with the advantage of a possible reference to a theoretical model of the activity in substitution of the taxonomies (see Sanchez \& Heene, 2010, table 1, p. 121), heavily impacted by the status given to the notion of resource and by the model used in information processing theories. Another consequence, extremely important concerning a long loop of regulation like this, would be to consider the material and symbolic resources as artefacts (Rabardel 1995), mediating the individual and collective activities. As for resources, usually nominated "human resources", they would be restored to their essence, that is to say as individual and / or collective competences, articulated with other, more specific or more general, including that ${ }^{15}$ of the firm itself. In such a case, linear logic (resources, competences, performance, presented in figure 2) would give way to another: articulation of individual and collective competences, which mediated by material and symbolic artefacts, would produce a performance.

\subsubsection{REGULATION TYPE “CHANGE OF SCHEME”}

Changes in search activity, such as those just mentioned, could encourage the emergence of regulations type "change of scheme". Indeed, the activity of the firm, considered as an articulation of individual and collective competences, which mediated by material and symbolic artefacts produce a performance, allows to apprehend it, sufficiently independent of its market relation, as an human activity, just comparable to many of the others that are not linked to a market logic. Thus, integrated in a very general human activity, it could be apprehended under a slightly different angle. One possible consequence would be then the questioning of its performance evaluation criteria. For example, the criteria of profitability or competitive advantage - inherited from the structure of the industry and that the resourcebased theory has not, apparently, called into question - could cease to be exclusive criteria of performance for benefit to others such as the social and environmental responsibility, which seem to prevail today and will be, probably, very important dependent variables, tomorrow. In such a case, it is therefore the scheme "description and explanation (or prediction) of the

\footnotetext{
${ }^{15}$ In the singular.
} 
differential performance of organizations" that would be changed in favour of another such as: "description and explanation of the specific human activity, facing to a market and producing, through material and symbolic artefacts, a socially recognized performance".

\subsection{Characteristics of this foresight approach}

Starting from an analysis of past evolutions of a given activity (here, the activity of research in management sciences) to consider, on this basis, three types of possible evolutions of this activity, is not without reminding the classic "scenarios method" (Godet, 1977) used in a foresight approach. Indeed, while the description of past research activities, in terms of scheme, could be assimilated to the "construction of the base", the three regulation loops would characterize respectively the elaboration of a "trend scenario" and two "contrasted scenarios" (Godet, 1977, pp. 93-95). Nevertheless, it can be noted that the logic involved in the two types of approach is very different. While the principle of "building scenarios" (Bootz, 2003) is essentially based on a methodological standard (development of the most likely scenario and, on this basis, contrasted scenarios), the prospective approach, that we have considered here, proceeds from a theoretical logic of the "activity regulations" described by MADDEC. Thus, the same theoretical framework allows the description of the present activity (as a "productive activity", expressed by "an instrumented scheme") and, using the three regulation loops of this activity ("constructive activity"), the specification of three types of new activities. Therefore, it is necessary to explain how:

- better achieve the same "productive activity" through changes in the organisation of rules of action (short-loop regulation);

- to design it differently thanks to a change of operative invariants (long loop regulation);

- to situate it differently in relation to some other activities (regulation of "change of scheme" type).

In other words, the evolutions, described in this way, refer more to an operationalization of a model specifying different modalities of restructuring of the studied activity, than to the building of various conjectures expressing the probabilistic contrasts required by the "scenarios method". MADDEC can therefore be considered as a theoretical guide of a foresight approach. That is what we have attempted to highlight through a rapid analysis of the evolution of research activities in management sciences.

\section{Conclusion}

The exercise undertook in this article had a double objective. On the one hand, it was to show how, the use of an activity analysis in research in management science, can lead to ask a number of questions about the conceptions, often implicit, that are conveyed in the domain and rarely discussed, so that they appear as evidences for the concerned community. Doing so, we have tried to show the strong impact of the concept of resource and the pervasiveness of information processing theories on the directions of these researches as well as some of consequences arising therefrom. On the other hand, it was to show how, a reading grid, theoretically founded in reference to the theories of activity, can have some relevance in adoption of a foresight reasoning. At this level, we would particularly emphasize that beyond its content, necessarily questionable, the foresight approach, envisaged from the loops of regulation of individual and collective human activities, happens to be very heuristic, while it is bringing elements of evidence that the management science and the developmental psychology have, certainly still, many things to say together.

\section{Références}


Arrègle, J.L., 1995. Le savoir et l'approche resource-based : une ressource et une compétence. Revue Française de Gestion (septembre-octobre), 84-94.

Barney, J., 1986. Strategic factor markets: Expectations, luck, and business strategy. Management Science (32), 1231-1241.

Barney, J., 1991. Firm resources and sustained competitive advantage. Journal of Management (17), 99-120.

Bootz, J.P. (2003). Prospective appliquée : création de connaissances et apprentissage organisationnel : construction d'un modèle explicatif fondé sur une approche cognitive. Thèse de doctorat, Paris : CNAM.

Bruner, J. S., 1983. Savoir faire, savoir dire : le développement de l'enfant. PUF, Paris.

Caves, R. E., 1980. Industrial organization, corporate strategy and structure. Journal of Econotnic Literature (58), 64-92.

Cohendet, P., Llerena, P., 1999. La conception de la firme comme processeur de connaissances. Revue d'économie industrielle (88), 211-235.

Conner, K.R., Prahalad, C.K., 1996. A resource-based theory of the firm: knowledge versus opportunism. Organization Science 7 (5), 477-501.

Coulet, J.C., 2011. La notion de compétence : un modèle pour décrire, évaluer et développer les compétences. Le Travail Humain 74 (1), 1-30.

Coulet, J.-C., 2013a. Comprendre les dynamiques internes et évolutives de l'activité humaine. In : Brégeon, J., Mauléon, F. (Eds.). Développement durable; l'enjeu compétences. ESKA Editions, Paris.

Coulet, J.-C., 2013b. Expérience et compétence : de la théorie à la pratique. Éducation Permanente (197), 125-137.

Coulet, J.-C., 2014. La conceptualisation dans l'activité individuelle et collective. Implications pour le management des connaissances et des savoirs. Revue Internationale de Psychosociologie de gestion des Comportements Organisationnels 19 (49), 135-158.

David, P.A., Foray, D., 2002. Une introduction à l'économie et à la société du savoir. Revue Internationale des Sciences Sociales 1 (171), 13-28.

Depeyre, C., 2005. Retour sur la théorie des ressources. Le Libellio d'Aegis (1), 9-14. https://hal-polytechnique.archives-ouvertes.fr/hal-00262991/document

Durand, T., 2000/2006. L'alchimie de la compétence. Revue Française de Gestion 1 (160), 261-292.

Feldman, M. S., Pentland, B. T., 2003. Reconceptualizing organizational routines as a source of flexibility and change. Administrative Science Quarterly (48), 94-118.

Gilbert, P., Raulet-Croset, N., Mourey, D., Triomphe, C., 2013. Pour une contribution de la théorie de l'activité au changement organisationnel. @GRH 2 (7), 67-88.

Godet, M., 2007. Crise de la prévision ; essor de la prospective : exemples et méthodes. PUF, Paris.

Hayes, R., Wheelwright, S., Clark, K., 1988. Dynamic Manufacturing: Creating the Learning Organization. Free Press, New York.șep:

Kuhn, T.S., 1983. La structure des révolutions scientifiques. Flammarion, Paris.

La Ville (de), V.I., Leca, B., Magakian, J.L., 2011. Vygotski aujourd'hui en management. Management \& Avenir 2 (42), 78-88.

Leplat J., 2006. La notion de régulation dans l'analyse de l'activité. Pistes, 8 (1), 1-25.

Lorino, P., 2009. Concevoir l'activité collective conjointe : l'enquête dialogique. Étude de cas sur la sécurité dans l'industrie du bâtiment. @ctivités 6 (1), 87-110.

Lorino, P., 2013. L'activité collective, processus organisant. Un processus discursif fondé sur le langage pragmatiste des habitudes. @ ctivités 10 (1), 221-242.

March, J. G., 1991. Exploration and exploitation in organizational learning. Organization Science (2), 71-87. 
Nelson, R.R., Winter, S.G., 1982. An evolutionary theory of economic change. Harvard University Press, Cambridge.

Nonaka, I., Takeuchi, H., 1995. The knowledge creating company: how Japanese companies create the dynamics of innovation. Oxford University Press, New-York.

Pastré P., 1997. Didactique professionnelle et développement. Psychologie Française 42 (1), 89-100.

Pastré, P., Mayen, P., Vergnaud, G., 2006. La didactique professionnelle. Revue française de Pédagogie (154), 145-198.

Penrose, E., 1959. The Theory of the Growth of the Firm. Oxford University Press, Oxford.

Pesqueux, Y., Durance, P., 2004. Apprentissage organisationnel, économie de la connaissance : mode ou modèle ? Cahiers du LIPSOR Série Recherche (6).

http://hal.archives-ouvertes.fr/docs/00/50/96/72/PDF/Apprentissage_oa_anisatfinal.pdf

Piaget, J., 1974 a. La prise de conscience. PUF, Paris.

Piaget, J., 1974 b. Réussir et comprendre. PUF, Paris.

Piaget, J., 1967. Biologie et connaissance. Gallimard, Paris.

Piaget, J., 1975. L'équilibration des structures cognitives: problème central du développement. PUF, Paris.

Porter, M., 1980. Competitive Strategies: Techniques for Analyzing Industries and Competitors. Free Press, New York (1998).

Porter, M., 1985. Competitive Advantage. Free Press, New York.șepi

Prahalad, C.K., Hamel, G., 1990. The core competence of the corporation. Harvard Business Review (may-june), 79-91.

Prévot, F., Brulhart, F., Guieu, G., 2010. Perspectives fondées sur les ressources. Proposition de synthèse. Revue Française de Gestion 5 (204), 87-103.

Samurçay, R., Rabardel, P., 2004. Modèles pour l'analyse de l'activité et des compétences, propositions. In : Samurçay, R., Pastré, P. (Eds). Recherches en didactique professionnelle. Octarès, Toulouse, pp. 163-180.

Sanchez, R., 1996. Strategic product creation: Managing new interactions of technology, markets, and organizations. European Management Journal 14 (2), 121-138.

Sanchez, R., 2008. A scientific critique of the resource-based view (RBV), with competencebased remedies for the RBV's conceptual deficiencies and logic problems. Research in Competence-Based Management (4), 3-78

Sanchez, R., Heene, A., 2010. Grande théorie et théorie intermédiaire en stratégie. Une perspective épistémologique. Revue française de gestion 5 (204), 105-125.

Schneuwly, B., Bronckart, J.P., 1985. Vygotsky aujourd'hui. Delachaux \& Niestlé, Neuchâtel.

Schumpeter, J. A., 1942. Capitalism, Socialism, and Democracy. Harper, New York.

Spender, J.C., Grant R.M., 1996. Knowledge and the firm: overview. Strategic Management Journal (17), 5-9.

Teece, D. J., 1976. The Multinational Corporation and the Resource Cost of International Technology Transfer. MA: Ballinger, Cambridge.

Teece, D. J., 1986a. Transactions cost economics and the multinational enterprise. Journal of Economic Behavior and Organization (7), 21-45.

Teece, D. J., 1986b. Profiting from technological innovation. Research Policy 15 (6), 285305.

Teece, D. J., 1988. Technological change and the nature of the firm. In : Dosi, G., Freeman, C., Nelson, R., Silverberg, G., Soete, L. (Eds.). Technical Change and Economic Theory. Pinter Publishers, New York, pp. 256-281.

Teece, D.J., 2007. Explicating dynamic capabilities: the nature and microfoundations of enterprise performance. Strategic Management Journal (28), 1319-1350. 
Teece, D. J., Pisano, G., Shuen, A., 1997. Dynamic capabilities and strategic management. Strategic Management Journal 18 (7), 509-533.

Rabardel, P., 1995. Les hommes et les technologies; approche cognitive des instruments contemporains. A. Colin, Paris.

Vergnaud, G., 1990. La théorie des champs conceptuels. Recherche en Didactique des Mathématiques 10 (2/3), 133-170.

Vygotski, L., 1934/1985. Le problème de l'enseignement et du développement mental à l'âge scolaire. In : Schneuwly, B., Bronckart, J.P., (Eds). Vygotski aujourd'hui. Delachaux \& Niestlé Neuchâtel.

Vygotski, L., 1934/1997. Pensée et langage (3ème ed.). La Dispute, Paris.

Wernerfelt, B., 1984. A resource-based view of the firm. Strategic Management Journal (5), 171-180.

\section{Biographical endnote}

Jean-Claude COULET, Research Fellow in developmental psychology, is currently an associate member of the LP3C, Université Rennes 2 and the open lab. "Exploration and Innovation" of the CRCGM, University of Auvergne. His research focuses on the modeling of competence for the analysis of individual and collective activities. In particular, it works in territories and organizations on the management of innovation, but also in the field of education and training, the APC and the professionalization of trainers. 